\title{
O financiamento do desenvolvimento territorial no Jequitinhonha mineiro entre 2003-2015
}

\author{
Financing and management of territorial development: the PROINF in \\ Minas Gerais Jequitinhonha between 2003/2015
}

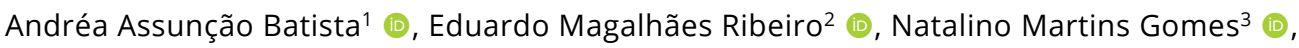
Andréa Narciso de Paula ${ }^{4}$ (1)

'Secretaria de Estado de Educação de Minas Gerais (SEE/MG), Montes Claros (MG), Brasil. E-mail: cibergeo01@gmail.com ${ }^{2}$ Universidade Federal de Minas Gerais (UFMG), Montes Claros (MG), Brasil. E-mail: eduardoribeiromacuni@gmail.com ${ }^{3}$ Instituto Federal do Norte de Minas Gerais (IFNMG), Araçuaí (MG), Brasil. E-mail: natalino.gomes@ifnmg.edu.br;

${ }^{4}$ Universidade Estadual de Montes Claros (Unimontes), Montes Claros (MG), Brasil. E-mail: andreapirapora@yahoo.com.br
\end{abstract}

How to cite: Batista, A. A., Ribeiro, E. M., Gomes, N. M., \& Paula, A. N. (2021). O financiamento do desenvolvimento territorial no Jequitinhonha mineiro entre 2003-2015. Revista de Economia e Sociologia Rural, $59(2)$, e215057. https://doi.org/10.1590/1806-9479.2021.215057

\begin{abstract}
Resumo: Este artigo analisa seis projetos de infraestrutura implantados nos Territórios da Cidadania do Alto e Médio Jequitinhonha financiados com recursos do PROINF, ação do governo federal de estímulo ao desenvolvimento territorial que oferecia incentivos à descentralização, governança local e gestão social. Usando informações recolhidas em fontes oficiais, estudos técnicos e pesquisas de campo, o artigo revela avanços e obstáculos desse programa. Os resultados da análise indicam que projetos mais enraizados no Território tinham maiores chances de sucesso, que a ampliação da escala geográfica e econômica quase sempre apresentou sérios riscos e que a própria concepção do programa implicava em limitações para gestão participativa. Conclui-se que o sucesso, mesmo parcial, depende, sobretudo, da relação construída ao longo da história entre a iniciativa e seu público.
\end{abstract}

Palavras-chave: gestão social, agricultura familiar, territórios, Jequitinhonha.

\begin{abstract}
This article analyzes six infrastructure projects implemented on the Citizenship Territories from the Upper and Middle Jequitinhonha, financed with resources from PROINF, a federal government action that stimulate territorial development and offered incentives for decentralization, local governance and social management. Using information gathered from official sources, technical studies and field research, the article shows advances and obstacles of this program. The results of the analysis indicate that projects more rooted in the Territory present a greater chance of success, that the expansion of the geographic and economic scale almost always presented serious risks, and that the very conception of the Program implied limitations for participatory management. It is possible to conclude that success, even if partial, depends mainly on the relationship built throughout the history between the initiative and its public.
\end{abstract}

Keywords: social management, family agriculture, territories, Jequitinhonha.

\section{Introdução}

Desde 1996, a partir do Programa Nacional de Fortalecimento da Agricultura Familiar (PRONAF), o governo federal criou programas que tinham por escopo expandir a produção agrícola familiar no Brasil. Nessas iniciativas, a infraestrutura ocupou posição importante, pois, além de necessitar de sementes e mudas, o agricultor carecia de equipamentos para preparo do solo, plantio, transporte, beneficiamento e vendas. O primeiro programa de alcance nacional dedicado a suprir essa demanda foi criado em 1997: o PRONAF Infraestrutura e Serviços Municipais. Em seguida, e decorrente da avaliação desse programa, surgiu, em 2003, a Ação de Apoio a Projetos de Infraestrutura e Serviços, ou, resumindo, 
PROINF. Associado aos Territórios Rurais, gerido pela Secretaria de Desenvolvimento Territorial do Ministério de Desenvolvimento Agrário (SDT/MDA), o PROINF combinava esforços pelo desenvolvimento com captação de demandas locais e cogestão por atores sociais, a denominada gestão social.

$\mathrm{Na}$ época, com base em metodologias semelhantes, foram criados outros programas, como PROMESO e CONSAD, que estimulavam descentralização, gestão social e desenvolvimento territorial nas áreas de turismo, formação de pessoas, segurança alimentar e extensão rural. Mas, entre todas as iniciativas, as mais duradouras, disseminadas, participadas e inovadoras foram aquelas dos Territórios Rurais, que, em 2008, converteramse parcialmente em Territórios da Cidadania. Com alcance nacional e normas de gestão muito elaboradas, o PROINF aperfeiçoou a metodologia do PRONAF/Infraestrutura e atendia aos colegiados territoriais, comissões de participação paritária do poder público e da sociedade civil que elegiam prioridades de investimentos. Entre 2003 e 2015, cada Território criou e geriu seu Plano Territorial de Desenvolvimento Sustentável (PTDRS), que orientou a aplicação dos recursos definidos nos editais anuais abertos pelo PROINF, que foi a principal ferramenta de indução à participação no desenvolvimento territorial.

Em Minas Gerais, ao longo desse período, o PROINF alocou R\$ 60 milhões em 13 Territórios: 349 projetos diversificados receberam investimentos no valor médio anual não corrigido de $\mathrm{R} \$ 172$ mil. Com três territórios constituídos e atuantes desde o início do programa, o Vale do Jequitinhonha recebeu $\mathrm{R} \$ 17,5$ milhões - 29\% dos investimentos feitos em Minas Gerais. O Território do Baixo Jequitinhonha enfrentou dificuldades de organização e captou parcela pouco relevante, de maneira que os recursos foram investidos principalmente nos Territórios do Alto e Médio Jequitinhonha, contemplados com valores expressivos quando comparados aos demais Territórios mineiros.

Alto e Médio Jequitinhonha alocaram quase o mesmo montante, mas investiram recursos de acordo com diferentes métodos e prioridades. Uma parte desses investimentos alcançou sólidos resultados, enquanto a outra enfrentou sérios problemas, principalmente quando foram apoiadas grandes estruturas de beneficiamento de produtos agrícolas com propósito de aperfeiçoar cadeias produtivas da agricultura familiar. Muitas dessas estruturas ficaram inconclusas, abandonadas ou subutilizadas por falta de complementação dos investimentos pactuados, dificuldades de reposição de peças ou ausência de normas de gestão.

O PROINF é uma experiência ímpar: com mais de uma década de atuação, recebeu expressiva alocação de recursos e atraiu participação social organizada e contínua. Considerando o acervo de dados existente e a participação social na gestão e avaliação, há necessidade e condição para avaliar a contribuição desse programa para o desenvolvimento territorial. É este o objetivo deste artigo: analisar projetos emblemáticos implantados nos Territórios da Cidadania (TC) do Alto e Médio Jequitinhonha, estudando alocação de recursos, negociações, gestão e abrangência territorial, para fazer um balanço dessa experiência duradoura e fecunda de descentralização de investimentos governamentais.

\section{O cenário}

O conceito de "território", a princípio, era usado, principalmente, por geógrafos em referência à área geográfica soberana de um Estado. No decorrer do tempo, incorporando elementos da economia e sociologia, território passou a ser compreendido como espaço delimitado por meio e a partir das relações de poder emanadas do Estado e de grupos sociais, incluindo usos, conflitos, identidades, sentimentos, enfim, compreendendo as relações entre a população e o espaço (Raffestin, 1993; Candiotto, 2004). Conforme Haesbaert (2005), território ganhou conotação material e simbólica, passou a ser relacionado à dominação jurídico-política do espaço e à sua apropriação efetiva por uma população.

Foi essa abordagem sofisticada - que permite associar território a possibilidades de desenvolvimento e se abriga, por exemplo, nos trabalhos de Abramovay (2000), Pecqueur (2005) e Ortega (2008) - que balizou a política pública brasileira. Abramovay (2000) foi pioneiro nessa reflexão ao propor substituir a abordagem setorial dualista (agricultura/indústria; urbano/rural) pela abordagem espacial nas políticas de desenvolvimento. Na mesma direção, 
Pecqueur (2005) enfatizou a necessidade de integrar ações dos atores sociais e do Estado para identificar recursos e ativos específicos do território e torná-los capazes de reestruturar as economias, criando reações singulares à incapacidade do capitalismo e da globalização para homogeneizarem o desenvolvimento. E Ortega (2008) identificou no território a condição para criar arranjos socioprodutivos a partir da organização dos atores, construindo projetos que vão além da economia, orientados por forças que refletem interesses das comunidades humanas e levam os atores sociais a participar da gestão e dos rumos das políticas públicas. Mas é preciso lembrar que essa concepção de território se fundamentou também na emergência de ambiente como tema relevante, pois a reflexão sobre desenvolvimento territorial necessitava incorporar as práticas costumeiras de manejo de recursos e valorizar as relações das populações com o meio em que viviam (Zhouri \& Laschefski, 2010).

Até a década de 1980, as políticas centralizadas predominavam no Brasil. Segundo Ortega (2008), foi com a emergência dos movimentos sociais, o fim da ditadura e a redemocratização que surgiram estímulos para participação, descentralização e desenvolvimento local. Esse "espírito de época" se materializou na Constituição Federal de 1988, e as ações descentralizadas respondiam a pressões "de cima" - agências multilaterais, órgãos públicos - e "de baixo" - reivindicações de movimentos sociais. O território, enfim, tornou-se um método para formular programas públicos.

Agricultura familiar surgiu como categoria política no Brasil na década de 1990. Analisando a gênese do conceito, Ortega (2008) o relacionou à mobilização de agricultores organizados, o que se refletiu nos estudos acadêmicos e, por fim, nas políticas públicas ao se converter em prioridade nas áreas de abastecimento, pobreza rural, segurança alimentar e desigualdades regionais.

Desde 1979, o Congresso da Confederação Nacional dos Trabalhadores da Agricultura (CONTAG) reivindicava uma política pública "voltada para o pequeno produtor". Em 1993, no governo Itamar Franco, foi esboçado o PRONAF, oferecendo crédito diferenciado (Grisa \& Schneider, 2014). Em 1997, foi criado o PRONAF Infraestrutura e Serviços Municipais, linha desse programa que, entre 1997-2002, financiou a fundo perdido a criação, ampliação e modernização de estruturas e equipamentos produtivos para municípios com presença expressiva de agricultores familiares. Para receber recursos, o município deveria apresentar projeto elaborado pelos recém-criados Conselhos Municipais de Desenvolvimento Rural Sustentável e Solidário (CMDRSS), fóruns de caráter consultivo, deliberativo e fiscalizador, formados com participação de representantes de órgãos estatais e da agricultura familiar (Ortega, 2008)

A avaliação do PRONAF Infraestrutura e Serviços no fim dos anos 1990 apontou a apropriação de recursos pelas prefeituras municipais, ou "prefeiturização", conforme Abramovay (2000). Eram formulados projetos pouco criativos, com caráter estritamente agrícola e produtivista. Segundo esse autor, essas características contrariavam as diretrizes do programa, que propunham adaptá-lo às demandas locais, e para isso seria essencial a participação de atores sociais na condução dos projetos. Essa avaliação aprofundou convergências entre as discussões sobre desenvolvimento rural e território, indicando que a dimensão intermunicipal propiciaria melhores condições para a gestão social e para enraizar os projetos nas demandas sociais (Niederle, 2014; Sabourin, 2014).

Território entrou para a política pública no Brasil a partir de 2003, com o Programa de Desenvolvimento Sustentável dos Territórios Rurais (PRONAT), vinculado à Secretaria do Desenvolvimento Territorial (SDT) do Ministério de Desenvolvimento Agrário (Brasil, 2005). Os territórios reuniam municípios vizinhos, com identidades sociais, econômicas, ambientais, históricas e culturais, com presença expressiva da agricultura familiar, baixo IDH e assentamentos da reforma agrária. Em 2007, quando o PRONAT foi avaliado, foi percebido que seu caráter era quase que exclusivamente agrícola e que mantinha pouca articulação com o conjunto das demandas sociais. Então foi criado o Programa Territórios da Cidadania (PTC), visando a uma maior amplitude, alcance intersetorial e transversal, reunindo agências públicas e integrando programas do governo federal. Chegaram a ser 135 as ações de 15 ministérios, que passavam por direitos humanos, desenvolvimento social, organização da produção, saúde, saneamento, acesso à água, educação e cultura, infraestrutura e ações fundiárias. Mas a criação do PTC não encerrou as ações do PRONAT. Os dois programas 
coexistiram em Territórios diferentes, receberam recursos, direção e animação do Ministério de Desenvolvimento Agrário. ${ }^{1}$ As ações do PTC foram coordenadas pela Casa Civil da Presidência da República, e as atividades fundamentalmente agrárias e agrícolas dos Territórios Rurais, pelo Ministério do Desenvolvimento Agrário (Bonnal, 2013; Niederle, 2014).

Para a organização do território, qualquer que fosse sua natureza, era necessário formar o colegiado territorial com representação paritária do poder público e da sociedade civil em todas as instâncias. O colegiado compreendeu agricultores familiares, assentados, sindicatos, associações, quilombolas e organizações não governamentais dos municípios. O colegiado funcionava por meio de plenárias, reunidas geralmente a cada semestre para debater propostas e planejar sua ação. Era composto do Núcleo Diretivo ou Dirigente, grupo reduzido formado por membros do colegiado incumbidos de encaminhar urgências de caráter executivo; do Núcleo Técnico, que oferecia apoio especializado às ações do colegiado; e das Câmaras Temáticas, instâncias incumbidas de tratar temas específicos, como mulheres, cadeias produtivas, educação e juventude (Jesus, 2014; Freitas, 2015). O desenho da organização variou, mas certo é que, quando se tornou unidade de ação pública, território se converteu também em unidade de gestão social, estimulando a participação da sociedade. Essa inovação na gestão, compreendida como "processo gerencial dialógico em que a autoridade decisória é compartilhada entre os participantes da ação" (Tenório, 2008, p. 158), orientou o governo federal na montagem da política, embora a cultura local, o mandonismo, e, por vezes, a própria dinâmica do programa limitassem a participação.

O enfoque territorial encontrou dificuldades, mas criou novas relações de poder: estimulou a participação de organizações de agricultores, descentralizou ações, reduziu a influência das elites locais e propôs outras bases para políticas até então pautadas pela troca de favores (Niederle, 2014). A escala espacial do programa rompeu as fronteiras municipais; então, prefeituras tiveram que partilhar decisões sobre investimentos e admitir a importância dos colegiados territoriais formados por representantes de vários municípios, da sociedade civil e do poder público. Isso limitou a "prefeiturização" dos recursos financeiros (Abramovay et al., 2010; Delgado \& Grisa, 2014; Sabourin, 2014).

O extinto MDA geriu o programa ao longo de toda a sua duração, e a principal fonte de financiamento dos territórios, rurais ou da cidadania, foi o PROINF, cujo desenho original remontava ao PRONAF Infraestrutura e Serviços e tinha por objetivo equipar territórios a partir de suas próprias demandas. Editais anuais definiam diretrizes para os projetos: itens financiáveis, público-alvo, perfil dos proponentes e requisitos para análise das propostas. Colegiados territoriais elaboravam Planos Territoriais de Desenvolvimento Rural Sustentável e enviavam ao MDA propostas em acordo com os planos e os editais anuais do PROINF (Brasil, 2012).

Até 2015, o edital anual do PROINF era lançado pela SDT/MDA no início do segundo semestre. Conhecendo suas diretrizes, o colegiado convocava plenária na qual seriam apresentadas, analisadas e votadas as propostas elegíveis. Geralmente era apresentado um esboço de projeto à plenária, que era aprovado e submetido à SDT, que avaliava os projetos, sua adequação às exigências do edital, certificava sua escala territorial e, finalmente, aprovava a proposta. Então o projeto seguia para a Caixa Econômica Federal, que depositava o recurso para o proponente adimplente. Como recursos públicos só podiam ser transferidos a entes da federação, o programa só admitia como proponente órgãos públicos municipal, estadual ou federal; na maioria das vezes, era uma prefeitura municipal que executava o projeto sob fiscalização do colegiado territorial (Jesus, 2014; Freitas, 2015).

O PROINF e a política territorial estabeleciam condições que precisavam ser consideradas pelas organizações dos Territórios. Mas essas condições nem sempre asseguravam a efetividade do programa, e, se ocorreram avanços, também surgiram muitas dificuldades nos projetos. Os estudos sobre o PROINF revelaram seus pontos positivos e

\footnotetext{
${ }^{1}$ Por exemplo: em Minas Gerais, foram criados 13 Territórios; em 2007, 9 foram transformados em Territórios da Cidadania (Alto, Médio e Baixo Jequitinhonha, Vale do Mucuri, Serra Geral, Noroeste de Minas, Alto Rio Pardo, Sertão de Minas e Águas Emendadas - este partilhado entre Minas Gerais, Goiás e Distrito Federal); outros 4 permaneceram Territórios Rurais: Alto Suaçuí Grande, Médio Rio Doce, Serra do Brigadeiro e São Mateus. A metodologia de atuação era idêntica: dirigidos por Colegiados Territoriais com participação paritária de organizações de Estado e da sociedade civil, decidiam sobre prioridades, ações e recursos.
} 
negativos. Sabourin (2014) listou como resultados positivos o fortalecimento da capacidade de planejamento dos atores, a aprendizagem individual e coletiva, a representação de agricultores familiares e a emergência de novas categorias de lideranças, como mulheres e jovens. Mas o autor citou também o reduzido número de projetos inovadores, a apropriação de equipamentos e estruturas pelas prefeituras, a lentidão da liberação dos recursos e a ausência de ações conjuntas dos ministérios. Delgado \& Grisa (2014) expuseram como negativas as limitações dos projetos para atender aos segmentos mais empobrecidos da população, a predominância de projetos agrícolas e a escassez de propostas para grupos urbanos, mulheres e jovens. Ainda, notaram que os projetos eram voltados, sobretudo, para produção e comercialização, desprezando temas como acesso à terra e relações com mercados. Assim, havia subaproveitamento de recursos e grande número de projetos parados ou não iniciados. No entanto, e apesar dos problemas, os autores destacaram a participação dos agricultores na política territorial e a criação de projetos relacionados às realidades locais como os principais avanços do programa. Por fim, Niederle (2014) observou que o programa não conseguiu integrar rural e urbano, alcançando o rural, mas não a dimensão territorial; no entanto, abriu espaços para participação de agricultores organizados, que, em certas circunstâncias, podiam neutralizar o mandonismo local. Outros trabalhos apontaram obstáculos do programa, como ausência de motivação dos agentes e desarticulação dos colegiados (Tarsitano et al., 2013), falta de celeridade na execução dos contratos, descumprimento de acordos (Souza \& Hespanhol, 2014), caráter setorial e exclusivo dos projetos e pouca participação das prefeituras nos colegiados territoriais (Nunes et al., 2015).

Mas existem consensos entre os autores que avaliaram o programa: houve esforço para estimular a participação de agricultores; foram feitas adequações para melhorar seu desempenho; foram alcançados resultados positivos pontuais na dinamização dos sistemas produtivos, na agregação de valor à produção e na melhoria da renda dos beneficiários, notadamente quando agricultores familiares passaram a ter acesso aos mercados locais. Ao reunir avaliações feitas por tantos autores, foi possível perceber semelhanças na identificação dos problemas - manutenção do foco no rural e persistência da dominação do poder público municipal - e nos avanços, que podem ser resumidos em crescimento da capacidade de gestão social e de conduzir projetos enfocados na realidade dos Territórios.

\section{Metodologia}

A metodologia usada na pesquisa que deu base a este artigo combinou três fontes de informações: a) literatura; b) dados secundários; c) dados de pesquisa de campo.

A primeira fonte de informação, literatura, forma o quadro analítico e factual que sustenta a interpretação dos dados secundários e de campo.

Em seguida, foram utilizados dados quantitativos do PROINF nos territórios, fundamentais para compreender os tipos de projetos e a operacionalização do programa. Os agentes no Território exercitaram sua concepção de desenvolvimento, priorizando certos dispêndios, hierarquizando temas e gerindo projetos. Informações sobre o andamento dos projetos, como tipos de investimentos, proponentes, objetivos, avaliações e gastos, detalhados por ano e território, foram encontradas no banco de dados do PROINF, no Sistema de Gestão Estratégica (SGE), da extinta SDT/MDA. Esses dados foram analisados por tipo de dispêndio e agrupados por "categorias de investimentos"; assim, foi possível compreender montante de investimentos dos Territórios.

A terceira fonte de informações veio de pesquisa de campo. Foi usada amostragem não probabilística intencional, baseada nos critérios de categorias de projetos e montante de investimentos para compor o panorama do PROINF nos Territórios. Ponderando esses critérios, o Núcleo Diretivo do Território da Cidadania do Alto Jequitinhonha (TCAJ) indicou a Escola Família Agrícola do município de Veredinha, o Entreposto de Mel do município de Turmalina e a Frutivale no município de Datas. O Núcleo Diretivo do Território da Cidadania do Médio Jequitinhonha (TCMJ) indicou como projetos emblemáticos para análise Escola Família Agroecológica de Calhauzinho no município de Araçuaí, Retroescavadeira do município de Ponto dos Volantes e Abatedouro no município de Comercinho. 
Escolhidos os projetos, cada Núcleo Diretivo indicou informantes que tinham relação com os projetos e a política territorial: membros de Núcleos Diretivos, gestores e beneficiários dos projetos. Com os núcleos eram investigados a origem, os interesses, a abrangência, a negociação e a avaliação dos projetos. Além disso, gestores foram entrevistados sobre implantação, gestão, abrangência e cotidiano do projeto. Por fim, era visitado o projeto e eram feitas entrevistas com os beneficiários em relação ao funcionamento, atendimento e avaliação do projeto.

Durante três meses consecutivos, no segundo semestre de 2016, em cada Território foram realizadas 20 entrevistas. Agentes de desenvolvimento conduziram os pesquisadores aos informantes, facilitando as entrevistas. A situação se tornava delicada quando havia problemas de funcionamento nos projetos, ou quando, tratando com prefeituras, o gestor municipal entrevistado se desresponsabilizava por ações de mandatos passados. As entrevistas permitiram identificar fatores locais, estruturais e conjunturais que influíram na concepção e funcionamento dos projetos e determinaram seus graus diversos de sucesso.

A pesquisa de campo produziu novos conhecimentos sobre os Territórios, ao vincular informações quantitativas e teóricas às empíricas, ao propiciar o encontro com os sujeitos das ações e ao permitir perceber nuances que, muitas vezes, escapam aos documentos escritos e são postas em questão referencial teórico e dados quantitativos. Sobretudo, passando da literatura para dados primários qualitativos, a pesquisa permitiu relacionar o quadro geral da política pública com as especificidades da sua execução nos Territórios, bem como possibilitou entender as circunstâncias peculiares e os resultados, positivos ou negativos, alcançados no esforço de criação de infraestrutura para a agricultura familiar. 0 método qualitativo permitiu compreender as perspectivas dos atores sociais e contrastar essas informações com dados quantitativos. Jesus (2014), Tarsitano et al. (2013) e Nunes et al. (2015), analisando projetos PROINF, utilizaram técnicas semelhantes para entender o PRONAT e associaram técnicas, combinando dados primários, aplicação de questionários e visitas aos locais.

Quando os pesquisadores passaram da literatura para os dados de campo, surgiram dificuldades para conectar temas gerais, como desenvolvimento, gestão social, políticas públicas e participação com a escala territorial e microlocal. Afinal, como uma categoria sofisticada como "desenvolvimento" era operada no cotidiano de um Núcleo Diretivo, que tende a ser afeito às demandas corriqueiras da política local? Nessa transição, que funde escalas na passagem da abordagem teórica para a gestão cotidiana dos Territórios, muitas vezes o pesquisador é levado à postura de etnógrafo, pois deve ler as categorias macroscópicas nas categorias êmicas - próprias do lugar, com suas especificidades e vieses para perceber de que modo, por exemplo, "gestão social" e "participação" se manifestam em uma máquina agrícola. Esse, afinal, é um exercício induzido pela pesquisa de campo para compreender a dicotomia entre determinações da política territorial e estratégias políticas locais, porque a concepção teórica de desenvolvimento do território se transforma, concretamente e ao longo de uma década, em um conjunto de projetos e práticas de gestão social relidos, ou lidos de maneira muito própria, pelos agentes de desenvolvimento territorial.

Os resultados estão apresentados a seguir, seguindo escalas de aproximação que possibilitam entender a história dos seis projetos analisados no artigo.

\section{Resultados}

\subsection{Os Territórios}

A bacia do rio Jequitinhonha fica a nordeste do estado de Minas Gerais. Com elevado percentual de população rural e economia baseada na agricultura e serviços, ocupa posição emblemática no estado. Graças à especialização produtiva, aos indicadores socioeconômicos e aos fluxos migratórios, desde os anos 1960 recebeu investimentos de programas que estimulavam atividades de grande escala. Esses programas geraram resultados modestos, acentuaram a concentração fundiária com a tomada de terras de agricultores para plantar 
eucaliptos e agudizaram problemas ambientais com florestas homogêneas, barragens e mineração. Paralelamente, a agricultura familiar da região criou, a partir das comunidades rurais, organizações autônomas que fortaleceram associações, sindicatos, agências religiosas e não governamentais (Ribeiro, 2013).

Com base em diversidades demográficas, fisiogeográficas, históricas e econômicas, o PRONAT dividiu a região em três Territórios da Cidadania: Alto, Médio e Baixo Jequitinhonha, O Alto Jequitinhonha foi povoado desde o século XVIII a partir do "Distrito Diamantino". Com o refluxo da mineração, a população se voltou para lavouras e "catas" de minério, e para um movimento contínuo de migração rio abaixo, na direção do que viria a ser, depois, o Médio Jequitinhonha. Nesse ponto, lavradores migrantes do alto rio se encontraram com imigrantes baianos, que, a partir dos fins do século XIX, estabeleceram uma rota contínua de abertura das matas que terminaria no Baixo Jequitinhonha (Graziano \& Graziano Neto, 1983).

Situado no domínio do Cerrado, o Alto Jequitinhonha é marcado pela paisagem de "grotas" e "chapadas", com terras de grotas muito partilhadas entre agricultores familiares e chapadas cobertas por eucaliptais de grandes empresas. O Médio Jequitinhonha, situado no Semiárido e coberto pela Caatinga, é caracterizado pelo complexo latifúndio-minifúndio (Ribeiro, 2013). A situação espacial dos dois Territórios aparece na Figura 1.

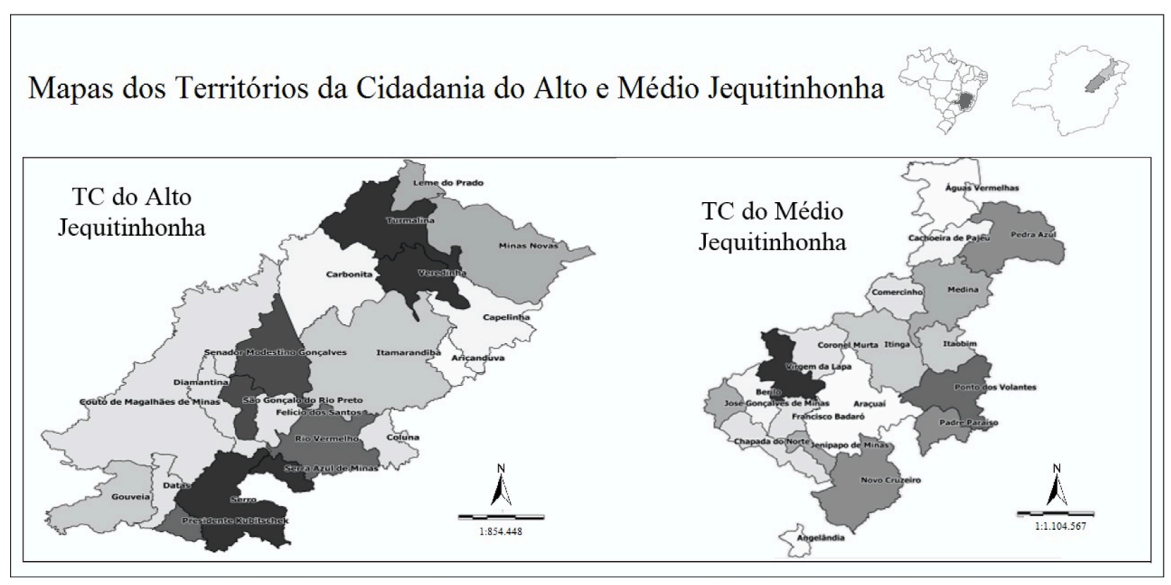

Figura 1 - Territórios da Cidadania do Alto e Médio Jequitinhonha.

O Território da Cidadania do Alto Jequitinhonha compreendia 19.578,30 km², abrangendo 20 municípios com população total de 280.827 habitantes, dos quais 35,93\% viviam na área rural. O Território da Cidadania do Médio Jequitinhonha abrangia $18.509,30 \mathrm{~km}^{2}$, compreendendo 19 municípios e população total de 287.396 habitantes, com $44,90 \%$ na zona rural. Nos dois Territórios, além da expressiva presença de agricultores familiares, existiam assentamentos, comunidades quilombolas e indígenas. Apresentavam Índices de Desenvolvimento Humano médios e próximos: 0,69 no Alto Jequitinhonha e 0,65 no Médio Jequitinhonha (Brasil, 2010).

O PROINF foi uma experiência coletiva e continuada de descentralização de investimentos públicos nos TCs do Alto e Médio Jequitinhonha. Dados da SGE/SDT/MDA revelam que o maior volume de investimentos aconteceu no período 2007/2008 e que a maioria dos recursos (62\%) foi aplicada em edificações e aquisição de equipamentos. A política territorial recebeu apoio de organizações de agricultores, e, desde 2003, a proposta foi abraçada por associações e sindicatos de trabalhadores rurais nos dois Territórios, principalmente pelo ITAVALE (Instituto de Trabalhadores e Trabalhadoras do Vale do Jequitinhonha) no Médio Jequitinhonha e pelo CAV (Centro de Agricultura Alternativa Vicente Nica) no Alto Jequitinhonha, agências dedicadas à organização da agricultura familiar, que nortearam os Territórios, influíram nos eixos de ação e projetos criados, que, muitas vezes, eram frutos de propostas em andamento, potencializadas pela política territorial. Graças a essa animação, juntos os TCs do Médio e Alto Jequitinhonha absorveram 28,57\% do investimento total do PROINF em Minas Gerais: R\$ 17 milhões, com média histórica de $\mathrm{R} \$ 1,4$ milhão por ano ou $\mathrm{R} \$ 700$ mil por território/ano (Tabela 1). 
Tabela 1 - Investimentos PROINF em Minas Gerais, valores históricos, 2003-2015.

\begin{tabular}{ccc} 
Território da Cidadania & Investimento (R\$) & Percentual de Minas Gerais (\%) \\
Médio Jequitinhonha & $10.100 .028,47$ & 16,86 \\
Alto Jequitinhonha & $7.026 .348,08$ & 11,71 \\
Total investido em Minas Gerais & $59.989 .309,68$ & 100,00 \\
\hline
\end{tabular}

Fonte: dados adaptados de SGE/SDT/MDA (Brasil, 2015).

O TCAJ investiu esses recursos, principalmente, em equipamentos $(34,17 \%)$, apoio às cadeias produtivas da agricultura familiar (31,36\%), edificações (20,34\%) e educação do campo $(3,46 \%)$, que consumiram $89,33 \%$ dos seus investimentos. O TCMJ - território que mais captou recursos do PROINF em Minas Gerais - investiu em aquisição de equipamentos (62,65\%), educação do campo $(11,23 \%)$, apoio às cadeias produtivas $(7,86 \%)$ e recursos hídricos $(7,05 \%)$, que absorveram 88,79\% dos investimentos (Brasil, 2015).

Dos investimentos do PROINF no TCAJ, a Frutivale absorveu em anos sucessivos o total de $R \$ 652.053,72$, ou $9,28 \%$ dos recursos despendidos no Território. Ao longo dos três anos de funcionamento, o investimento beneficiou 60 agricultores, com despesa média de $\mathrm{R} \$ 10.867,56$ por beneficiário. A EFAV gastou $\mathrm{R} \$ 243.373,00$, ou $3,46 \%$ dos investimentos do TCAJ, com 480 beneficiários diretos entre 2012-2016, despendendo $R \$ 507,03$ por beneficiário. Por fim, o Entreposto absorveu R $\$ 338.348,33$, ou 4,82\% da despesa do TCAJ, e até fins de 2016 não havia entrado em funcionamento.

Já no TCMJ, o Abatedouro consumiu R $\$ 130.000,00$, ou 1,29\% dos investimentos do Território, sem resultados. A EFAC absorveu $\mathrm{R} \$ 386.778,00$, ou 3,82\% dos investimentos, beneficiando diretamente 600 estudantes entre 2011-2016, representando média de $R \$ 644,63$ por beneficiário. A Retroescavadeira teve investimento de $R \$ 200.000,00$, ou 1,98\% dos investimentos do Território, beneficiando 300 produtores, com despesa média de $\mathrm{R} \$ 666,67$ por beneficiário.

\subsection{Dinâmica dos projetos}

Dos projetos analisados no TCAJ e TCMJ, em 2016 apenas as Escolas Famílias Agrícolas (EFAs) funcionavam plenamente, mas cada projeto tinha sua peculiaridade.

Depois de edificado, o Entreposto de Mel de Turmalina não conseguiu se adequar às normas sanitárias, pois, para processar e comercializar, requeria ainda mais investimentos. A associação beneficiada pelo projeto organizava mutirões de usuários potenciais para adequálo, buscava parcerias para custear os ajustes necessários e comercializava o mel por meio de empresas parceiras.

A Frutivale funcionou por três anos depois da construção e, em seguida, teve problemas na gestão e nos mercados. Em 2016, a processadora estava paralisada por carecer de adequar a estrutura física às normas sanitárias. Além disso, enfrentava questões judiciais por suspeita de desvio de recursos, falsificação de documentos e irregularidades financeiras. Por fim, como acumulava dívidas elevadas, a nova gestão municipal abandonou o projeto. ${ }^{2}$

A EFA de Veredinha recebia anualmente 120 estudantes do Território no ensino secundário, contava com apoios da prefeitura municipal, do CAV e do programa estadual de custeio das EFAs ("Bolsa-Aluno"), além de suporte de universidades parceiras. No entanto, tinha dificuldades com transporte de estudantes, espaço nos prédios, insuficiência de material escolar, falta de equipamentos básicos e de área experimental. Além disso, vivia o risco constante de corte no apoio financeiro caso mudasse o gestor municipal. Por fim, havia o desafio de consolidar uma equipe estável e qualificada para educação no campo.

A EFA de Araçuaí enfrentava um quadro semelhante àquele de Veredinha: funcionava com plena capacidade, contava com apoio da prefeitura municipal e do programa estadual, mas havia insuficiência de espaço, problemas com abastecimento de água, rotatividade de professores, escassez de recursos para custeio e insegurança em caso de mudança na gestão municipal, o que poderia comprometer o apoio financeiro.

\footnotetext{
${ }^{2}$ Nunes et al. (2015) encontraram situações semelhantes em estudos nos Territórios do Rio Grande do Norte.
} 
O Abatedouro de gado bovino em Comercinho estava inconcluso: foi travado por pendências financeiras e ambientais, e então abandonado. Em 2016, terminado o recurso do PROINF, a empreiteira abandonou o projeto, e a prefeitura municipal não se dispunha a completá-lo.

$\mathrm{Na}$ Retroescavadeira, por fim, a utilização intensa provocou desgastes que geravam despesas elevadas de manutenção para a prefeitura e, às vezes, falta de atendimento para as comunidades que a solicitavam. Sucateada depois de cinco anos de uso, foi leiloada.

\subsection{Negociação dos projetos}

Um projeto podia entrar com três tipos de apoios diferentes nas plenárias dos Territórios pleiteando recursos do edital anual do PROINF: 1) fazendo parte de demandas consolidadas de grupos de agricultores. Neste caso, o projeto já tinha sido muito debatido e reunia um consenso sólido entre seus apoiadores; por exemplo, as escolas famílias agrícolas e da apicultura, que podem ser tipificadas como demandas históricas; 2) o projeto faria parte de potenciais considerados inexplorados e, então, reuniria algum consenso entre agentes de desenvolvimento. O consenso era insuficiente para gerar apoios incondicionais, mas suficiente para minar resistências; por exemplo, os casos de agroindustrialização e mecanização agrícola, que podem ser tipificadas como demandas construídas; 3) o projeto poderia usar a conjuntura da abertura do edital e reunir interesses dispersos para criar um consenso momentâneo, mas suficientemente forte, para captar os recursos; por exemplo, a dotação de equipamentos e edificações para as prefeituras municipais, que podem ser tipificadas como demandas de oportunidade.

No longo prazo, a experiência do PROINF no Jequitinhonha mostrou que os tipos de apoio que sustentaram as demandas influenciaram o destino dos projetos. Territórios são espaços de identidade e consenso, bem como de dissensões, que influíam nos debates, orientavam negociações e criavam projetos com grandes diferenças de método. A origem da demanda, agregando mais ou menos apoio para se tornar um consenso, quase sempre influiu na conversão de uma ideia em projeto, porque implicava em maior ou menor suporte institucional, em mobilização de interesses pelo seu sucesso e, concretamente, na busca e oferta de aportes de recursos novos ou complementares. Nos casos analisados neste artigo, o tipo de demanda influenciou claramente na trajetória futura do projeto.

Desde a criação, os dois Territórios receberam apoio das organizações de base que tinham uma história de defesa de interesses da agricultura familiar. Ao longo dos anos, essas organizações consolidaram propostas que se tornaram consensos em temas como educação, água, conservação de recursos e comercialização. Essas propostas, mais que refletir interesses, mobilizavam grupos organizados que pressionavam por projetos temáticos.

Depois de constituídos os Territórios e os colegiados territoriais, as propostas históricas de grupos organizados de agricultores "capturaram" parte do PROINF, que, no TCAJ, converteu-se na EFA de Veredinha e no Entreposto de Mel; no TCMJ, transformou-se na EFA de Araçuaí. Demandas organizadas ao longo da história criaram propostas que se converteram em projetos também organizados e em associações, que geriram os empreendimentos com ativa participação do público-alvo. Por isso, conseguiram organizar os mutirões necessários para que as EFAs funcionassem, para readequar o Entreposto de Mel e para buscar recursos que sustentaram esses projetos nas horas críticas. Além disso, como faziam parte de um consenso para desenvolvimento rural, esses projetos se integraram a outras políticas públicas, seja reunindo juventude, inovação e tecnologia para a agricultura nas EFAs, seja reunindo qualidade da produção com busca de mercados e programas públicos de aquisição de alimentos, no caso do Entreposto.

Já iniciativas originadas de demandas construídas fizeram outro trajeto: a conjunção entre interesses e edital do PROINF permitiu captar os recursos, mas nem sempre sustentou organização, participação, aportes complementares e empenho suficiente para dar vida aos projetos. Assim, projetos que surgiram de demandas relevantes, mas pouco sedimentadas em grupos organizados de agricultores - casos da Frutivale no TCAJ e do Abatedouro no TCMJ -, receberam recursos do PROINF, porém encontraram dificuldades para manter o apoio organizado, principalmente nas circunstâncias adversas. Ambos surgiram do poder público, por 
influência da EMATER/MG, que encontrou no PROINF a possibilidade de apoiar cadeias produtivas. A negociação das propostas passou pelo Fórum do Território, mas os interesses que se articularam não foram suficientes para dar solidez e durabilidade aos projetos. Nesses casos, a ausência de engajamento das organizações de agricultores e/ou de desenvolvimento rural foi determinante para o fracasso dos projetos. Quando a Frutivale enfrentou problemas técnicos e de caixa, teve apenas o apoio da Prefeitura Municipal de Datas e da EMATER. As associações de produtores e o consórcio de prefeituras criados para apoiá-la não se responsabilizaram pela processadora, e o projeto naufragou. A trajetória do Abatedouro foi ainda mais resumida, pois faltou complementação de recursos da prefeitura municipal; em seguida, com a mudança de gestão, desapareceu a responsabilidade política pelo projeto.

A Retroescavadeira de Ponto dos Volantes, no TCMJ, aproveitou-se da combinação entre um edital do PROINF, que financiava maquinário, e a ausência de projetos na plenária do Território: típica demanda de oportunidade. Passou por negociação entre a prefeitura e o Sindicato de Trabalhadores Rurais do município, que usou as diretrizes do edital e o espaço de concertação do Fórum Territorial para vincular o uso do equipamento à conservação de estradas rurais e abertura de bacias de contenção para agricultores familiares. O acordo se manteve pela combinação entre a firmeza do Sindicato e a boa disposição de uma gestão municipal simpática às ações territoriais.

\subsection{Abrangência espacial dos projetos}

A abrangência espacial sempre foi critério importante na avaliação dos projetos pelos Territórios. Afinal, programas territoriais foram criados para, ao mesmo tempo, reduzir o clientelismo e o poder de decisão das prefeituras, para atender ao público de vários municípios e empoderar a sociedade. Por acordo, os projetos deveriam abranger ao menos três municípios.

Mas nem todos os projetos analisados neste artigo - e também nos dois Territórios alcançaram abrangência territorial. As duas EFAs, o Entreposto e a Frutivale atendiam a vários municípios, mas a Retroescavadeira e o Abatedouro atendiam apenas a um município. Embora esse aspecto fosse vital na política territorial, para os agentes de desenvolvimento dos Territórios essa situação se repetia com frequência, principalmente nos projetos de aquisição de equipamentos - que consumiram 2/3 dos investimentos do TCMJ e 1/3 do TCAJ. Isso revelava a dificuldade da política territorial para superar os limites do município, pois as prefeituras mantiveram domínio sobre montante considerável dos recursos e bens, mesmo com as correções de rumos e controles nas despesas do programa.

Apesar disso, houve um aspecto novo na relação entre prefeituras e recursos: a necessidade de negociação dos investimentos nos fóruns dos territórios. Para aprovar projetos de abrangência restrita a um município, sindicalistas e representantes da agricultura familiar negociavam aberta ou veladamente para alcançar dois propósitos: primeiro, trocar o apoio à prefeitura pelo apoio a projetos de interesse de agricultores; segundo, condicionar a aprovação da proposta restrita ao município à colocação do equipamento a serviço de agricultores familiares daquele mesmo município. O cumprimento desse segundo ponto negociado dependeu, evidentemente, da força do sindicato de agricultores do município, da sensibilidade e da continuidade da administração pública municipal. Essa negociação mostrou sua viabilidade, por exemplo, no uso da Retroescavadeira por comunidades rurais em Ponto dos Volantes. Mas, em outros casos, a prefeitura se escorava na inexistência de marco legal para regular os territórios e usava, a seu critério, edificações, obras ou equipamentos, ignorando demandas de agricultores do próprio município e argumentando que era legalmente impedida de compartilhá-los com outras prefeituras.

No entanto, alcançar abrangência territorial não assegurou necessariamente viabilidade ao projeto. Ao contrário, muitas vezes acentuou suas dificuldades. São emblemáticos os casos da Frutivale e do Entreposto, que, em 2016, não funcionavam mais ou encontravam dificuldade para funcionar, revelando um grande problema dos projetos de apoio às cadeias produtivas: combinar abrangência territorial com ganhos de escala na produção. Esses projetos (i) iam para além do município, (ii) envolviam agregação de valor e (iii) pressupunham ganhos econômicos de escala, ou seja: quase tudo que os projetos territoriais deveriam ter 
por escopo. Mas coordenar atuação, apoios e gestão em vários municípios foi uma dificuldade evidente para esses projetos.

Esses casos revelavam os problemas que surgiam quando ocorreram tentativas de transformar escala espacial em vantagem econômica, buscando ganhos na combinação de grandes equipamentos com abrangência territorial. Em 2016, estavam paralisados pelo menos seis outros projetos financiados pelo PROINF, os quais, nos dois Territórios, combinavam grande abrangência espacial com geração de valor na busca de ganhos econômicos. De acordo com levantamento feito pela Delegacia do MDA em Minas Gerais, em 2015 existiam dezenas de projetos PROINF em situação semelhante em outros Territórios enfrentando o mesmo problema. Resumindo, raros projetos de "inclusão produtiva" conseguiram dar o esperado salto de amplitude espacial nos Territórios, revelando que ampliar abrangência territorial na verdade abre novos desafios.

Mas é preciso destacar que um eixo de projetos conseguiu sucesso no alcance de escala territorial: a educação. As duas EFAs combinaram atendimento a muitos municípios e funcionamento regular. Deve ser ponderado, no entanto, que educação era tema de demanda histórica, contava com experiências sedimentadas desde a década de 1980, dispunha da assessoria de associação estadual especializada e contava com fonte institucionalizada de recursos de custeio, vinda do governo do estado para sustentar as escolas.

\subsection{Gestão dos projetos}

As propostas de projetos poderiam chegar às plenárias territoriais a partir de diversas origens: sindicatos, movimentos organizados, associações, agências do governo do estado e, claro, prefeituras municipais. Além disso, muitas propostas eram feitas por parceria entre organizações, mas a legislação exigia que o projeto fosse apresentado ao PROINF por ente público de uma das três instâncias da federação, que assumiria a responsabilidade pela execução. Assim, haveria um proponente real (sociedade civil, estado ou parceria entre ambos) e um proponente formal, responsável legal pelo projeto, que podia ser também o proponente real. De qualquer modo, os projetos da sociedade civil deveriam ser endossados por órgão estatal.

As plenárias que debatiam e escolhiam as propostas a serem financiadas eram concorridas e mobilizavam, sobretudo, o poder público municipal - o qual, geralmente, preferia ir a essas plenárias do que a outras. Isso sempre provocou desentendimentos, porque a ação da prefeitura poderia ser oportunista, apresentando proposta em seu próprio benefício ou em desacordo com os critérios definidos no colegiado territorial. Para evitar oportunismos, os colegiados incluíram como critérios para aprovar propostas a regularidade de participação nas reuniões, o número de participantes, a quantidade de projetos já orientados para o município, a obrigatoriedade de atender, no mínimo, a três municípios, o foco na agricultura familiar e a coerência com o Plano Territorial de Desenvolvimento.

Depois de selecionadas as propostas, tramitados os encaminhamentos e liberados os recursos, os projetos eram instalados sob responsabilidade de um órgão de Estado. Em seguida a gestão do projeto seria transferida para quem o propusera: prefeitura ou órgão público, associação ou comunidade, ONG ou sindicato.

Nos TCMJ e TCAJ, existiram três tipos de gestão.

Os projetos criados por demanda do poder público adotaram a gestão centralizada. Um órgão ou gestor estatal, quase sempre da prefeitura, era responsável pelo projeto, que era gerido como parte do patrimônio municipal, geralmente sem realçar a origem do recurso e sem participação de agricultores familiares. Isso podia se tornar um problema quando havia eleição de prefeito que não participara das negociações do projeto, como nos casos da Frutivale e do Abatedouro: geridos pelas prefeituras com alguma ajuda da EMATER, quando surgiram dificuldades estavam desguarnecidos de apoio dos usuários, do Território e do prefeito.

Associações procuraram criar gestões participadas. EFAs e Entreposto de Mel usaram como estratégias reuniões amplas e frequentes, seminários, mutirões para prover infraestrutura, doações de bens, promoção de eventos para obter recursos, visitas técnicas, 
capacitações, intercâmbios e, principalmente, parcerias diversificadas com instituições estatais e privadas. O incentivo à participação deu a esses projetos maior autonomia em relação ao poder público e, ao mesmo tempo, comprometeu os usuários com seu sucesso, estimulando o controle social, participado e coletivo. Mas a gestão participada se relaciona apenas aos projetos que atendiam às demandas históricas de grupos organizados. Nesses casos, quando surgiram impasses, houve empenho para buscar sustentação por conta da identidade entre os atores sociais e o projeto. A organização criada para a gestão se apropriava do projeto e assegurava sua autonomia na sucessão de mandatos municipais.

Por fim, foi usado um estilo misto de gestão, como no caso da Retroescavadeira. Associações e sindicato organizavam a demanda do equipamento gerido pela prefeitura, negociavam, chegavam a acordos que colocaram para o poder público obrigações com manutenção e custeio, e entregavam aos agricultores a gestão do agendamento dos serviços.

Assim, um objetivo do PRONAT - descentralizar ações e ampliar a participação no controle dos investimentos - foi alcançado, com organizações do Território governando destino, uso e conservação de projetos. No entanto, nem sempre foi possível para o Colegiado Territorial influir na gestão ou decidir sobre usos de bens e recursos nos projetos do PROINF. Embora o colegiado fosse decisivo no debate, negociação e aprovação do projeto, sua influência ficava limitada depois que órgãos públicos, principalmente prefeituras municipais - legalmente responsáveis pelo projeto -, controlavam o empreendimento ou passavam sua gestão a proponente da sociedade civil. O Núcleo Diretivo geralmente acompanhava a distância e, a não ser diante da necessidade de aprovar recursos adicionais para projetos já implantados, raramente se manifestava.

Foram muitas as explicações para que as coisas tomassem esse rumo.

Entre as dificuldades para acompanhar os investimentos no Território havia o descompasso entre a metodologia da política territorial e a realidade dos municípios, que permitia à prefeitura centralizar bens ou distribuí-los de acordo com sua conveniência. O rural geralmente ocupava lugar subalterno no jogo de poder no município, inclusive em municípios de população majoritariamente rural, e os interesses de agricultores familiares nem sempre conseguiam sensibilizar as prefeituras.

Além disso, havia entraves operacionais. Os Territórios dispunham de instâncias de gestão: Núcleo Diretivo e Núcleo Técnico. O primeiro tinha por função coordenar as ações definidas pelo plenário, articular atores sociais, instituições e políticas públicas. O segundo deveria assessorar o Território em temas específicos. No entanto, embora existisse a estrutura de gestão e os núcleos driblassem dificuldades para se reunir, deliberar sobre questões urgentes do Território e definir metodologias de trabalho, sempre faltaram tempo, recursos e estratégias para monitorar projetos.

Avaliando esse aspecto, lideranças de Territórios alegaram que tinham intenção de entregar aos usuários projetos sem tutela, só interferindo em caso de solicitação. Argumentaram também que a governança era dificultada pela ausência de personalidade jurídica dos Territórios. Outro impasse era a dificuldade de diálogo entre colegiado territorial e prefeituras municipais, pois o colegiado não tinha mandato e obedecia à dinâmica da plenária; prefeitos, por sua vez, têm mandatos de quatro anos. Assim, as relações podiam ser marcadas por afinidade em um mandato e conflito no mandato seguinte. Por fim, é preciso considerar que o trabalho de membros do colegiado e do Núcleo Diretivo era voluntário; seu custeio era fundamentado na doação de tempo feita pelo indivíduo ou pela sua organização de origem, e raramente havia tempo e dinheiro para visitar projetos com problemas.

Assim, a capacidade de governança do colegiado territorial realmente deveria ter sido como foi: parcial, restrita ou até mesmo inexistente. Em situação crítica, os projetos contavam apenas com seus próprios esforços para buscar recursos adicionais ou sustentação política.

\subsection{Avaliação pelos atores sociais}

O PROINF foi uma experiência inovadora de descentralização de gastos de recursos públicos que exigiu capacidade de gestão de organizações estatais e da sociedade civil dos Territórios para investir em infraestrutura. Nos Territórios, há unanimidade quanto à importância do programa ao viabilizar projetos, estimular discussões, possibilitar 
experiências novas, de grande e reduzido sucesso. Essa experimentação não aconteceu sem dificuldades: a concentração setorial, no agrícola e no rural, a rotatividade dos membros do colegiado territorial, a abrangência restrita ou municipalizada dos projetos, a incerteza na participação do poder público municipal, a desarticulação entre a política territorial e a prática local, a atuação tímida de Conselhos Municipais de Desenvolvimento, a ausência de suporte em estrutura e finanças, os entraves de gestão e as dificuldades com as escalas.

Apesar disso, o PROINF forçou uma discussão generalizada e contínua entre poder público e sociedade civil dos Territórios que repercutiu, em graus variados, nos municípios e foi mais densa naqueles onde havia organizações de base que se interessaram pela política territorial. Nesse sentido, foi necessária a movimentação pelo Território, articulando interesses de sindicatos e de movimentos sociais. O PROINF teve forte componente educativo, pois os agentes aprenderam a lidar com políticas públicas, compreenderam a lógica da descentralização de recursos, a dificuldade da gestão, negociaram interesses da sociedade e dos gestores municipais em fóruns abertos que induziam à negociação, aos acordos e ao respeito aos acordos. Para trafegar nessa política, agricultores familiares precisaram fortalecer suas redes de relações para sustentar propostas de projetos de infraestrutura, bem como respeitar posicionamentos antagônicos. Particularmente, devem ser destacados os esforços no eixo da educação rural - que absorveu quase $10 \%$ dos investimentos em todos os territórios de Minas Gerais em uma década. Investimentos em EFAs foram localizados em um município, mas, abertos a crianças e jovens do território, no conjunto dos casos, esses gastos se revelaram mais coerentes com os fundamentos dos programas de desenvolvimento territorial, dado o alcance amplo e as complementaridades sociais e culturais que exigiram. Com o tempo e a experiência, com erros e acertos, a proposta da política territorial se tornou compreensível para todos os participantes. Na opinião dos atores sociais, o PROINF desempenhou duas funções importantes: viabilizou projetos e permitiu diálogos entre grupos de interesses divergentes.

Mas o PROINF também mostrou seus próprios problemas. Certamente o principal deles era a restrição da gestão de bens pelo colegiado territorial, entregando-os para prefeituras municipais e outras agências da federação, reduzindo o poder fiscalizador do Território. Outro problema era o direcionamento que o edital anual dava aos projetos, restringindo a eleição de diretrizes e prioridades próprias dos territórios. O prazo exíguo de submissão das propostas era outro martírio para os Núcleos Dirigentes: entre a publicação do edital com diretrizes novas e rígidas e a entrega dos projetos corria um mês, reduzindo a oportunidade de negociar e elaborar melhor os projetos.

A "prefeiturização" continuou a existir, embora sujeita a novos acordos. O edital do PROINF acendia o apetite de muitas prefeituras, embora não de todas. Era o momento de "capturar" equipamentos para municipalizá-los ou desterritorializá-los, comprometendo as bases do programa, que acabava sendo, em certos momentos, reduzido a uma partilha anual de máquinas e edificações. Esse procedimento era ratificado - às vezes com uma certa complacência - por algumas organizações da agricultura familiar que admitiam a possibilidade de municipalizar bens diante da impossibilidade de usá-los para servir a todo o território. Os investimentos do PROINF, além de revelar as dificuldades dos Territórios para lidar com o programa, mostraram também a ambição modesta e a escassa criatividade de prefeituras, que muitas vezes se reduzia - com exceções notáveis, destaque-se - à aquisição e municipalização de máquinas e construções.

\section{Conclusões}

O PROINF revelou um grande cabedal de possibilidades e iniciativas não exploradas no Vale do Jequitinhonha. Apesar dos desafios, o programa abriu perspectivas, maturou experiências e consolidou alguns eixos - poucos é certo - que os próprios Territórios estabeleceram. Um balanço do PROINF nos dois Territórios da Cidadania mostrou que, para alcançar seus objetivos, o projeto não dependeu do volume investido: aportes menores apresentaram bons resultados; aportes maiores provocaram desperdício de recursos. Mostrou que, nas condições em que os Núcleos Dirigentes operavam, é praticamente impossível a governança dos investimentos - e esse foi um ponto frágil na metodologia do 
programa. Da mesma forma, mostrou que esforços para elevar a escala de produção em empreendimentos produtivos e coletivos da agricultura familiar ainda estão longe de alcançar bons resultados e que a gestão participada pode ser viável em projetos que partem de demandas históricas e consolidadas no Território. Revelou, igualmente, que a negociação do projeto influi na boa execução e alcance dos objetivos. Muito embora sejam práticas situadas em polos opostos na concepção de desenvolvimento rural que fundamentou o PROINF, a boa negociação pode levar ao sucesso projetos de aquisição de equipamento, desde que amparados em uma gestão dialogada e em experiências coletivas e amadurecidas de educação da juventude sustentadas por sólidos pactos territoriais.

Mas o PROINF revelou também que, por si só, um programa inovador, continuado e participado é incapaz de induzir inovações. Se o projeto não contasse com o tempero da história, da organização e da experiência, se não fosse abraçado como investimento de futuro por grupos do próprio Território, se não reunisse a força de um sólido pacto, as coisas não aconteceriam. Nesse sentido, o alcance dos objetivos do PROINF, contraditoriamente, associou-se mais à história local - a um encontro feliz entre o edital e as condições objetivas para efetivar o projeto - que à metodologia e à gestão do programa. Quando não se verificaram essas condições, a alternativa mais funcional foi distribuir recursos para equipar prefeituras, as quais são capazes de gerir e até de beneficiar grupos de agricultores familiares, desde que estes tenham representação que consiga, lastreada no fórum territorial, negociar os recursos em bases menos desiguais.

Desse modo, uma conclusão se impõe: o PROINF apoiou iniciativas que efetivamente alcançaram seus objetivos e obtiveram sucesso, mas nunca foi o definidor do sucesso. Certo é que, independentemente do PROINF, a iniciativa persistiria, sob forma de EFA ou Entreposto. Assim, o programa auxiliou quem estava - como dizem os agricultores - "caminhando", porém se revelou limitado para estimular saltos à frente. Por exemplo, Frutivale e Abatedouro foram propostas consistentes e certamente necessárias, mas, faltando-lhes o arranjo social de suporte, esvaíram-se, desperdiçando recursos materiais e humanos, resultando em desgastes, atritos e questões judiciais.

De outro lado, projetos de sucesso apoiados pelo PROINF foram transitivos. Demandaram múltiplos apoios, não representaram apenas uma organização e uma demanda, mas uma trajetória, um plano de trabalho e, sobretudo, uma rede histórica de parcerias - muito especializada, como no caso das EFAs. Neste sentido, as boas iniciativas buscaram seus próprios complementos, sob a forma de assessoria, recursos ou novos projetos, que contribuíram para diversificar mais a iniciativa na busca de sinergias.

É recomendável que programas do mesmo estilo sejam fundamentados na avaliação das capacidades acumuladas pelos proponentes dos projetos, principalmente na capacidade de mobilizar interesses e histórias do Território, que são as condições para criar o protagonismo essencial para a sustentação. O PROINF não é proposta acabada; é um instrumento que pode ou não atingir seus fins, a depender de acordos, negociações, arranjos e engajamentos fundamentalmente territoriais. A política pública, na verdade, nasce dessas condições.

Por fim, no Jequitinhonha, o PROINF teve o grande mérito de captar e executar ações que saíram da base da agricultura familiar. Ao executá-las, mostrou amarras que se distribuem por vários níveis: comunitários, municipais, territoriais, estaduais e federais. Cada nível, ainda, ramifica-se em numerosos eixos: produtivos, políticos, sociais, institucionais. Assim, operar a política pública na escala territorial permitiu identificar os níveis e eixos em que estão as amarrações. Infelizmente não forneceu, ao mesmo tempo, condição para desatá-las. Mas nem por isso a experiência do PROINF pode ser considerada negativa para esses Territórios. Ao contrário, foi um notável aprendizado de negociação de projetos, de gestão de recursos, de construção de arranjos sociais. Para o futuro - agora mais que nunca um futuro mais-que-perfeito - poderá servir como ensaio de aprendizado, de avaliação e aperfeiçoamento da governança de programas territoriais de desenvolvimento.

\section{Agradecimentos}

A pesquisa que deu origem a este artigo foi apoiado pelo CNPq, Fapemig e Territórios da Cidadania do Alto e do Médio Jequitinhonha, aos quais os autores agradecem. 


\section{Bibliografia citada}

Abramovay, R. (2000). O capital social dos territórios. Economia Aplicada, IV(2), 379-397.

Abramovay, R., Magalhães, R., \& Schroder, M. (2010). Representatividade e inovação na governança dos processos participativos: o caso das organizações Brasileiras de agricultores familiares. Sociologias, 12(24), 268.

Bonnal, P. (2013). Referências e considerações para estudo dos programas de desenvolvimento territorial (PRONAT e PTC) na perspectiva da redução da pobreza em territórios rurais. In C. Miranda \& B. Tiburcio (Eds.), Políticas de desenvolvimento territorial e enfrentamento da pobreza no Brasil. Brasília: IICA.

Brasil. Ministério do Desenvolvimento Agrário - MDA. Secretaria de Desenvolvimento Territorial - SDT. (2005). Marco referencial para apoio ao desenvolvimento de territórios rurais (Série Documentos Institucionais, No. 02-2005). Brasília: SDT.

Brasil. Ministério do Desenvolvimento Agrário - MDA. Secretaria de Desenvolvimento Territorial - SDT. (2010). Balanço de gestão: resultados das ações do Programa de Desenvolvimento Sustentável de Territórios Rurais (PRONAT) 2003-2010. Brasília: SDT/MDA.

Brasil. Secretaria de Desenvolvimento Territorial - SDT. (2012). Manual operacional do Proinf 2012: ação orçamentária de apoio a projetos de infraestrutura e serviços em territórios rurais. Brasília: SDT.

Brasil. Secretaria de Desenvolvimento Territorial - SDT. Ministério de Desenvolvimento Agrário - MDA. (2015). Banco de dados do Sistema de Gestão Estratégica (SGE). Recuperado em 1 de novembro de 2015, de sge.mda.gov.br

Candiotto, L. Z. P. (2004). Uma reflexão sobre ciência e conceitos: o território na geografia. In A. D. Ribas, E. S. Sposito \& M. A. Saquet (Eds.), Território e desenvolvimento: diferentes abordagens. Francisco Beltrão: Unioeste.

Delgado, N. G., \& Grisa, C. (2014). Políticas de desenvolvimento territorial e pobreza rural no Brasil: análise das institucionalidades e da governança. Estudos Sociedade e Agricultura, 22(1).

Freitas, A. F. (2015). Dinâmicas sociais e desenvolvimento territorial no Território Serra do Brigadeiro: atores, redes e instituições (Tese de doutorado). Universidade Federal de Minas Gerais, Belo Horizonte.

Graziano, E., \& Graziano Neto, F. (1983). As condições de reprodução camponesa no vale do Jequitinhonha. São Paulo. Perspectivas, 6, 85-100.

Grisa, C., \& Schneider, S. (2014). Três gerações de políticas públicas para a agricultura familiar e formas de interação entre sociedade e estado no Brasil. Revista de Economia e Sociologia Rural, 52(Suppl.1), 125-146.

Haesbaert, R. (2005). Da desterritorialização à multiterritorialidade. In Anais do X Encontro de Geógrafos da América Latina. São Paulo.

Jesus, C. M. (2014). Desenvolvimento territorial rural: uma análise comparada entre Territórios constituídos autonomamente e os induzidos pelas políticas públicas no Brasil e na Espanha (Tese de doutorado). Universidade Federal de Uberlândia, Uberlândia.

Niederle, P. A. (2014). Política local e a trama das relações de poder no desenvolvimento territorial. In J. S. B. Cavalcanti, M. N. B. Wanderley \& P. A. Niederle (Eds), Participação, território e cidadania. Recife: Editora UFPE.

Nunes, E. M., Tôrres, F. L., Silva, M. R. F., Sá, V. C., \& Godeiro-Nunes, K. F. (2015). Dinamização econômica e agricultura familiar: limites e desafios do apoio a projetos de infraestrutura (PROINF) em territórios rurais do Nordeste. Revista de Economia e Sociologia Rural, 53(3), 529-554.

Ortega, A. C. (2008). Territórios deprimidos. Uberlândia: Edufu.

Pecqueur, B. (2005). O desenvolvimento territorial: nova abordagem dos processos de desenvolvmento para economias do Sul. Raízes, 24(1), 10-22.

Raffestin, C. (1993). Por uma geografia do poder. São Paulo: Ática.

Ribeiro, E. M. (Ed.). Sete estudos sobre a agricultura familiar do Jequitinhonha. Porto Alegre. Editora da UFRGS, 2013.

Sabourin, E. (2014). Origens, evolução e institucionalização da política de agricultura familiar no Brasil. In Anais do Seminário sobre Agricultura Familiar Brasileira. Brasília: MDA.

Souza, S. P., \& Hespanhol, R. M. (2014). Interfaces entre desenvolvimento territorial e rural a partir da perspectiva dos territórios da cidadania do estado de São Paulo. In Anais do VI Congresso Iberoamericano de Estudios Territoriales y Ambientales. São Paulo. 
Tarsitano, R. A., Sant'Ana, A. L., \& Araújo, C. A. M. (2013). Análise dos projetos PROINF do Território Andradina, estado de São Paulo, período 2004 a 2011. Informações Econômicas, 43(3), 44-55.

Tenório, F. G. (2008). Um espectro ronda o terceiro setor, o espectro do mercado (3. ed.). ljuí: Editora da Unijuí.

Zhouri, A., \& Laschefski, K. (2010). Desenvolvimento e conflitos ambientais: um novo campo de investigação. Belo Horizonte: Editora UFMG.

\section{Submetido em: 5/Out/2018 \\ Aceito em: $18 / \mathrm{Jul} / 2020$}

Classificação JEL: Q18; R58. 